\title{
Screening and manipulation of L-glutamic acid Polymorphs by antisolvent crystallization in an easy- to-use microfluidic device
}

Huanhuan Shi ${ }^{a}$, Fei Li ${ }^{a}$, Xin Huang a , Ting Wang a ,Ying Bao ${ }^{\text {a,b }}$, Qiuxiang Yin a,b, Chuang Xie a,b,*, Hongxun Hao a,b,*

a National Engineering Research Center of Industrial Crystallization Technology, School of Chemical Engineering and Technology, Tianjin University, Tianjin 300072, China.

b Collaborative Innovation Center of Chemical Science and Engineering (Tianjin), Tianjin 300072, China.

Corresponding Author

*E-mail: hongxunhao@tju.edu.cn, acxie@tju.edu.cn

Tel: 86-22-27405754. Fax: +86-22-27374971.

\section{S1 Solubility measurement of L-glutamic acid in water + ethanol systems}

The solubility of L-glutamic acid (commercially available $\alpha$-form) was measured gravimetrically in water + ethanol solvent mixtures at $10,15,20^{\circ} \mathrm{C}$, respectively. Firstly, excess L-glutamic acid was added into solvents with different known mixing ratios. Experiments were conducted at a specified temperature by a thermostatic bath and the suspensions were agitated with a magnetic stirrer for a certain time to reach equilibrium. Then, the solutions were filtered by a syringe with a $0.22 \mu \mathrm{m}$ PTFE filter and introduced into a small beaker that had been previously dried and weighed. Subsequently, the beaker was put into a vacuum oven at $355.13 \mathrm{~K}$ for $24 \mathrm{~h}$ until the weight of beaker kept constant. Finally, the solubility was derived from the initial saturation solution mass and residual solute mass. All experiments were performed three times to obtain a mean value and all weighing operations were carried out with analytical balance $( \pm$ $0.0001 \mathrm{~g})$.

The solubilities of $\alpha$-form L-glutamic acid were measured by gravimetric method in solvent mixtures at 10,15 and $20^{\circ} \mathrm{C}$ as shown in Figure S1 - S3, respectively. Each data point is the average value of three groups of experiments. In addition, for the metastable $\alpha$-form crystals, the residual solute in the beaker was analyzed by PXRD to ensure that it contains $\alpha$-form. In this work, the solubility data was correlated by CNIBS/Redlich-Kister model to indicate the relationship between solubility and solvent compositions as Eq.1. ${ }^{1}$

$\ln x_{1}=x_{2} \ln \left(x_{1}\right)_{2}+x_{3} \ln \left(x_{1}\right)_{3}+x_{2} x_{3} \sum_{i=0}^{n} S_{i}\left(x_{2}-x_{3}\right)^{i}$

where $x_{1}$ is the mole solubility in water + ethanol solvent, $x_{2}$ and $x_{3}\left(x_{3}=1-x_{2}\right)$ are the initial mole composition of the mixed solvent, $S_{\mathrm{i}}$ is the model constant, $\mathrm{n}=0,1,2$ and $3 .\left(x_{1}\right)_{2}$ and $\left(x_{1}\right)_{3}$ represent the mole fraction of L-glutamic acid in pure solvent $i$ (ethanol 2 and water 3), respectively. In this research, $\mathrm{n}=2$, therefore, Eq.1 can be further simplified as Eq.2:

$\ln x_{1}=A_{0}+A_{1} x_{2}+A_{2}\left(x_{2}\right)^{2}+A_{3}\left(x_{2}\right)^{3}+A_{4}\left(x_{2}\right)^{4}$

where $A_{0}, A_{1}, A_{2}, A_{3}$ and $A_{4}$ are model parameters. The results are listed in Table $\mathrm{S} 1$ for $\alpha$-form and Table S2 for $\beta$-form.

The average relative deviation (ARD, Eq. 3) was used to evaluate the fitting of CNIBS/Redlich- 
Kister model as following:

$A R D=\frac{100}{N} \sum_{i=1}^{N}\left|\frac{\left(x_{1}^{\exp }-x_{1}^{c a l}\right)}{x_{1}^{\exp }}\right|$
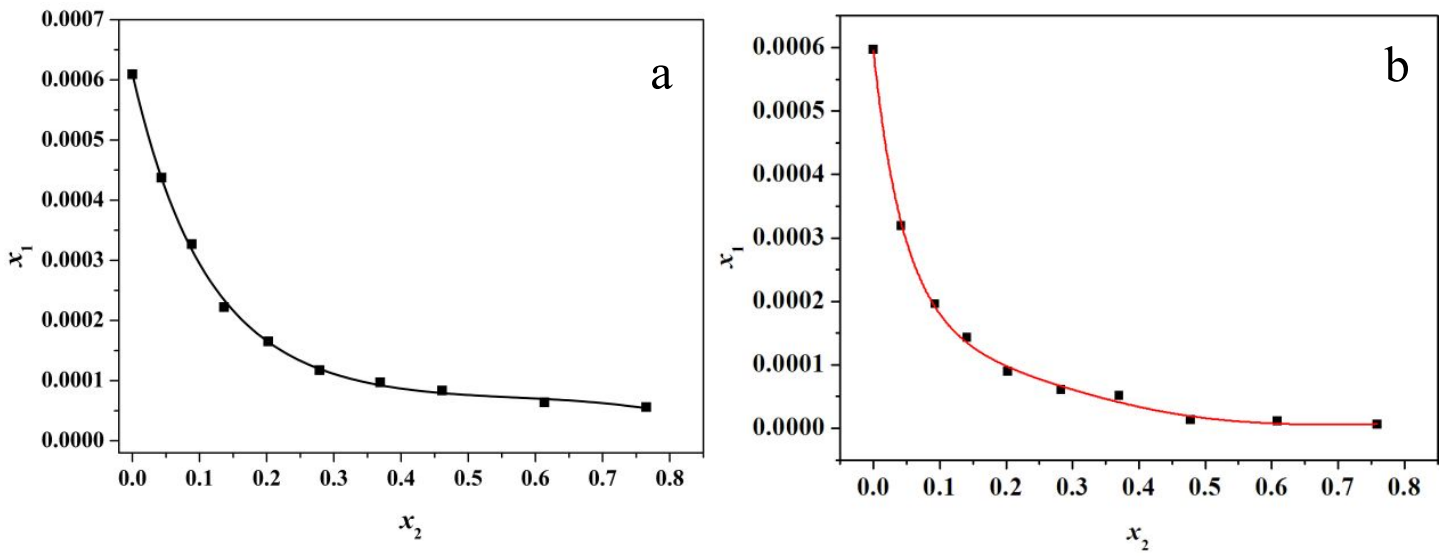

Figure S1. Mole fraction solubility $\left(x_{1}\right)$ of L-glutamic acid in water+ethanol at various mole fractions $\left(x_{2}\right)$ of ethanol at $10{ }^{\circ} \mathrm{C}$. (a) $\alpha$-form, (b) $\beta$-form. The experimental data is fitted by CNIBS/Redlich - Kister model.
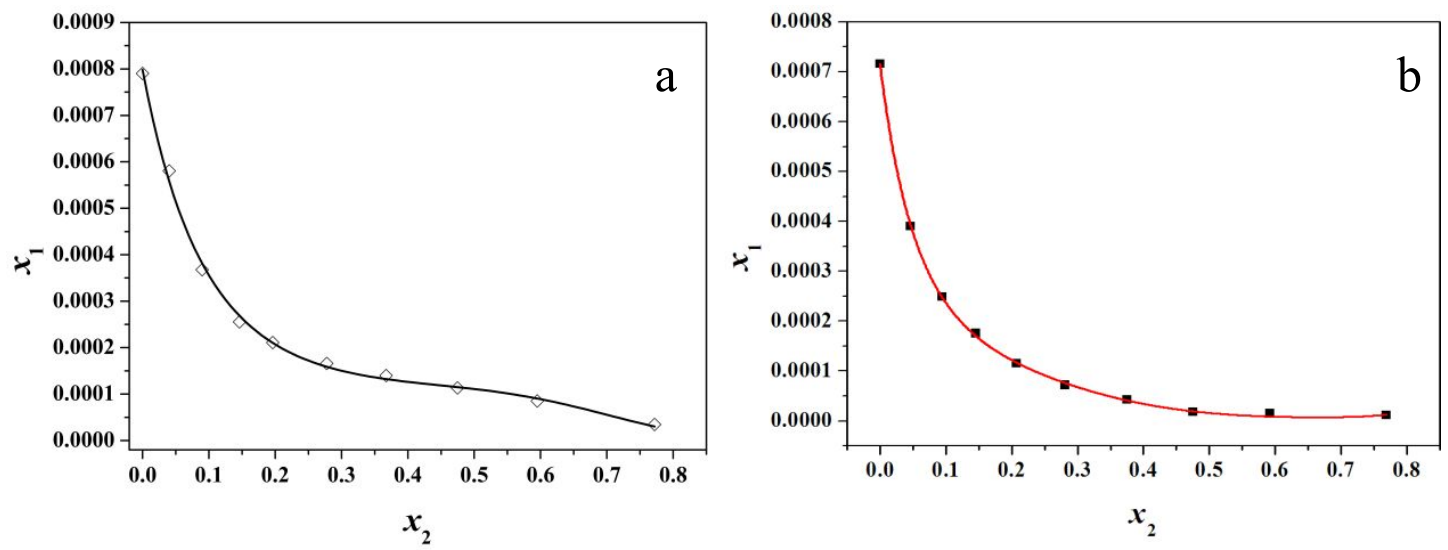

Figure S2. Mole fraction solubility $\left(x_{1}\right)$ of L-glutamic acid in water+ethanol at various mole fractions $\left(x_{2}\right)$ of ethanol at $15{ }^{\circ} \mathrm{C}$. (a) $\alpha$-form, (b) $\beta$-form. The experimental data is fitted by CNIBS/Redlich - Kister model.
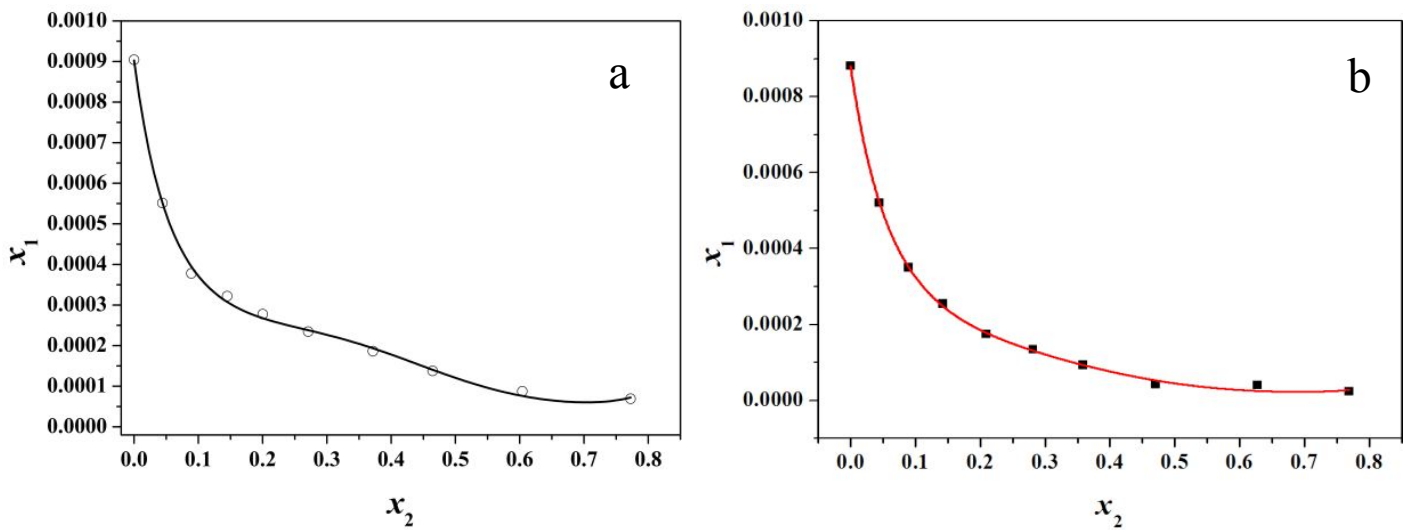
Figure S3. Mole fraction solubility $\left(x_{1}\right)$ of L-glutamic acid in water + ethanol at various mole fractions $\left(x_{2}\right)$ of ethanol at $20{ }^{\circ} \mathrm{C}$. (a) $\alpha$-form, (b) $\beta$-form. The experimental data is fitted by CNIBS/RedlichKister model.

Table S1. The fitted parameters of CNIBS/Redlich-Kister model for $\alpha$-form L-glutamic acid in water + ethanol solvent at different temperature.

\begin{tabular}{lllllll}
\hline$T(\mathrm{~K})$ & $A_{0}$ & $A_{1}$ & $A_{2}$ & $A_{3}$ & $A_{4}$ & $A R D$ \\
\hline 283.15 & -7.37863 & -9.17265 & 15.08179 & -12.06575 & 3.42701 & 2.61 \\
288.15 & -7.11318 & -10.76682 & 24.4476 & -24.52812 & 5.26535 & 1.65 \\
293.15 & -7.04388 & -11.61722 & 42.53103 & -77.98805 & 47.79133 & 2.62 \\
\hline
\end{tabular}

Table S2. The fitted parameters of CNIBS/Redlich-Kister model for $\beta$-form L-glutamic acid in water + ethanol solvent at different temperature.

\begin{tabular}{lllllll}
\hline$T(\mathrm{~K})$ & $A_{0}$ & $A_{1}$ & $A_{2}$ & $A_{3}$ & $A_{4}$ & $A R D$ \\
\hline 283.15 & -7.42571 & -16.86312 & 61.38402 & -127.12331 & 86.11891 & 1.46 \\
288.15 & -7.24283 & -14.96820 & 49.13103 & -108.63161 & 79.61172 & 0.68 \\
293.15 & -7.03502 & -13.50734 & 43.30841 & -84.76519 & 56.84481 & 0.87 \\
\hline
\end{tabular}

The value of $A R D(<3.00 \%)$ in Table.1 indicates that CNIBS/Redlich - Kister model is suitable for correlating solubility data in water + ethanol binary solvent system.

\section{S2 Mixing behavior between solutions and antisolvent in the microchannel}

To ensure that the solution is mixed evenly with the antisolvent before flowing out, a purple dye was added into solutions to characterize the mixing behavior. The microfluidic device was fixed under an optical microscope equipped with video camera. First of all, the channel length is long enough. Then, different flow rate conditions were adjusted by syringe pumps to observe the mixing performance in the mixing channel. As the two fluids flowed along the channel, a color change occurred between the purple dye solution and colorless antisolvent. When the two fluids were mixed completely, the color of the mixed solution gradually became uniform. Images were taken at different positions along the channel after the two fluids converged. Images of the mixed solutions at the fixed locations in Figure S4 - S6 indicate the uniformly mixed between solutions and antisolvent. During the experiments, the channel was extended to ensure crystal growth under the premise of complete mixing. In order to see the color in the channel more clearly, the brightness of the light maybe change, so the color shade is not the main basis of the investigation, and the mixed behavior is judged by the uniformity of color. 


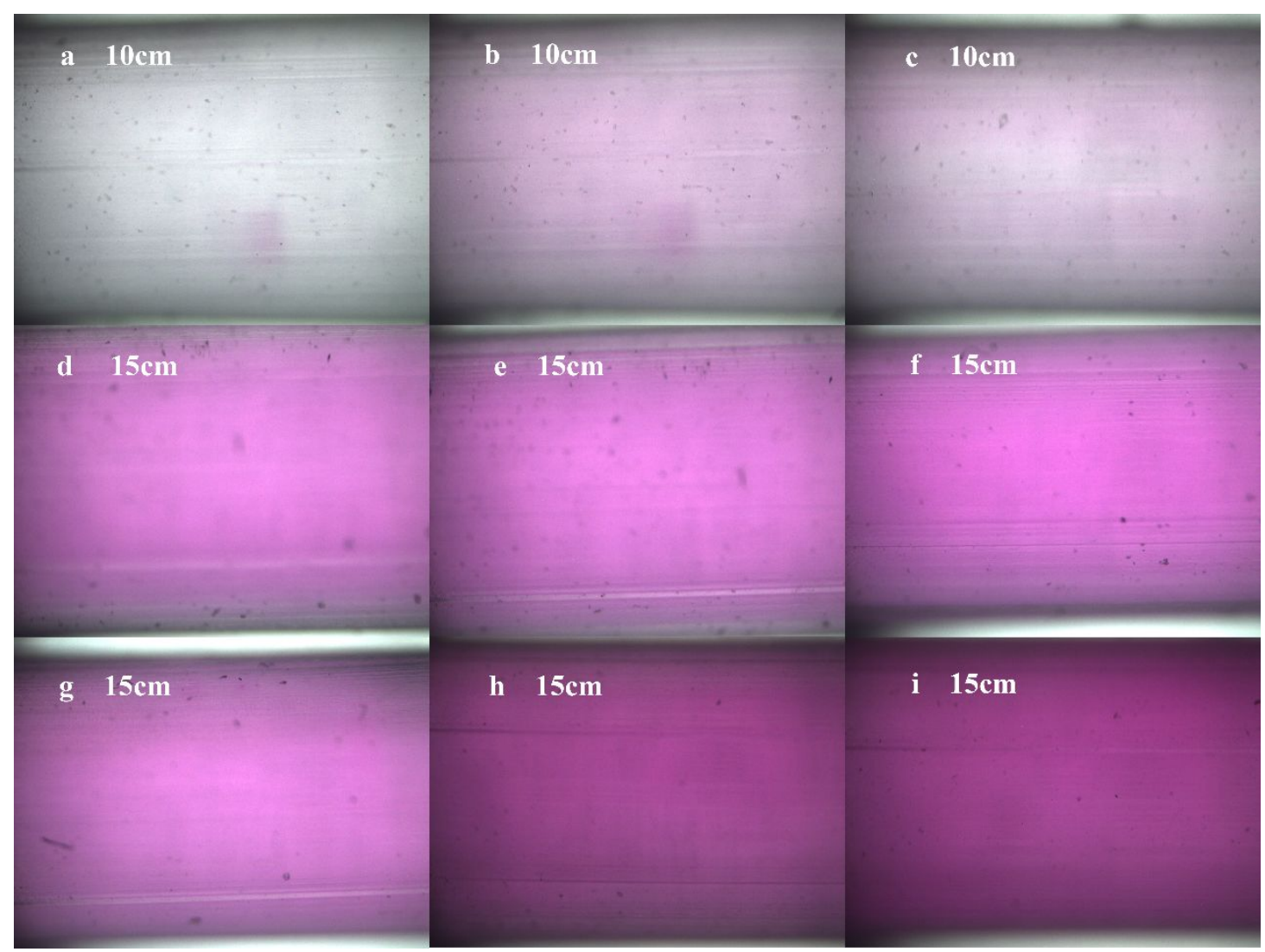

Figure S4. Microscope images of the mixed solutions at the fixed locations under different flow rates. The flow rate of antisolvent remained constant at $100 \mu \mathrm{L} / \mathrm{min}$, the flow rate of dye solution: a) $10 \mu \mathrm{L} / \mathrm{min}$, b) $20 \mu \mathrm{L} /$ min, c) $40 \mu \mathrm{L} /$ min, d) $60 \mu \mathrm{L} / \mathrm{min}$, e) $80 \mu \mathrm{L} / \mathrm{min}$, f) $100 \mu \mathrm{L} / \mathrm{min}$, g) $120 \mu \mathrm{L} / \mathrm{min}$, h) $140 \mu \mathrm{L} / \mathrm{min}$, i) $160 \mu \mathrm{L} / \mathrm{min}$. The length marked in the figure does not represent the point at which the mixture begins evenly. 


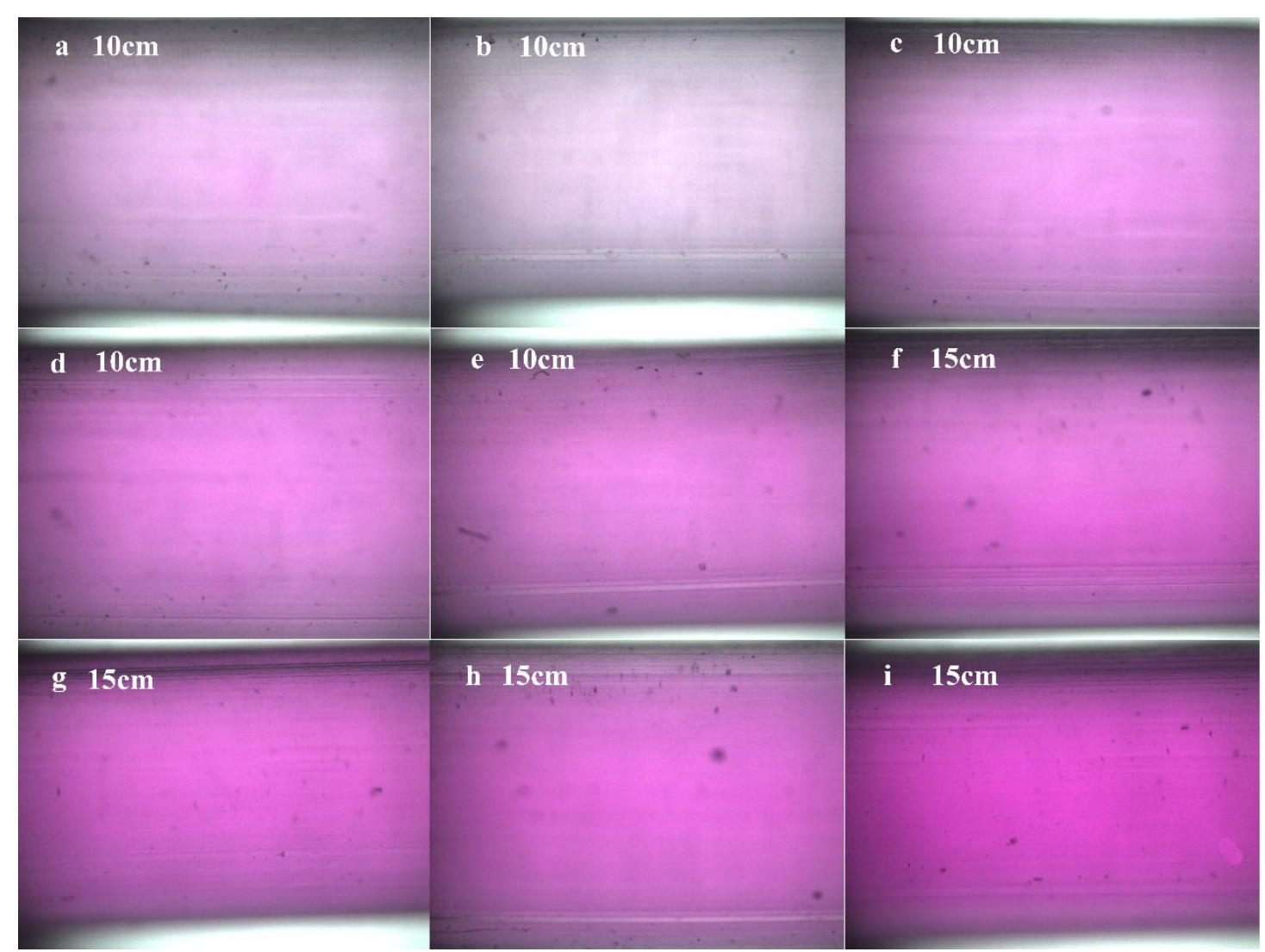

Figure S5. Microscope images of the mixed solutions at the fixed locations under different flow rates. The flow rate of antisolvent remained constant at $120 \mu \mathrm{L} / \mathrm{min}$, the flow rate of dye solution: a) $20 \mu \mathrm{L} / \mathrm{min}$, b) $40 \mu \mathrm{L} / \mathrm{min}$, c) $60 \mu \mathrm{L} / \mathrm{min}$, d) $80 \mu \mathrm{L} / \mathrm{min}$, e) $100 \mu \mathrm{L} /$ min, f) $120 \mu \mathrm{L} / \mathrm{min}$, g) 140 $\mu \mathrm{L} / \mathrm{min}$, h) $160 \mu \mathrm{L} / \mathrm{min}$, i) $180 \mu \mathrm{L} / \mathrm{min}$. The length marked in the figure does not represent the point at which the mixture begins evenly.

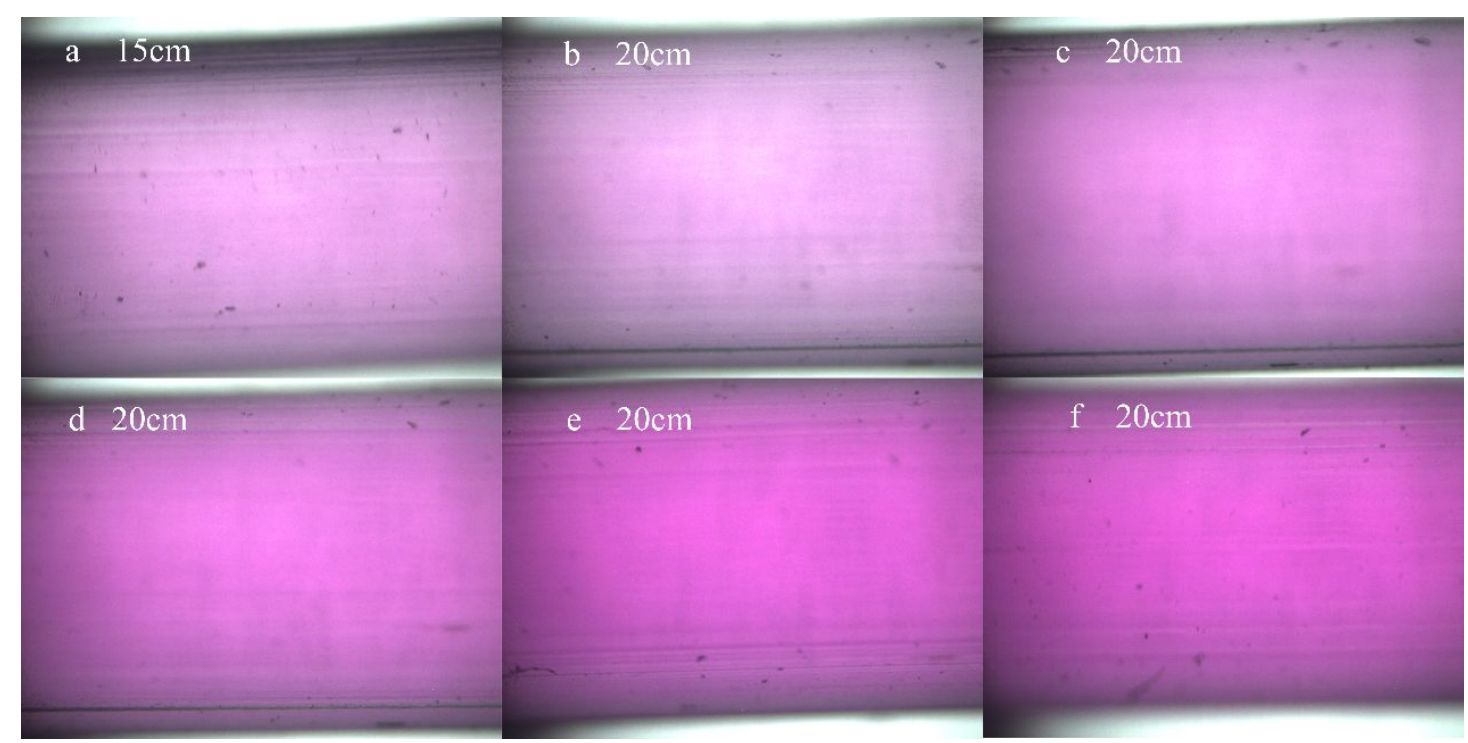

Figure S6. Microscope images of the mixed solutions at the fixed locations under different flow rates. The flow rate of antisolvent remained constant at $150 \mu \mathrm{L} / \mathrm{min}$, the flow rate of dye solution: a) $40 \mu \mathrm{L} / \mathrm{min}$, b) $60 \mu \mathrm{L} / \mathrm{min}$, c) $90 \mu \mathrm{L} / \mathrm{min}$, d) $120 \mu \mathrm{L} / \mathrm{min}$, e) $150 \mu \mathrm{L} / \mathrm{min}$, f) $180 \mu \mathrm{L} / \mathrm{min}$. The length marked in the figure does not represent the point at which the mixture begins evenly. 
S3 Polymorph selectivity and final supersaturation under various conditions
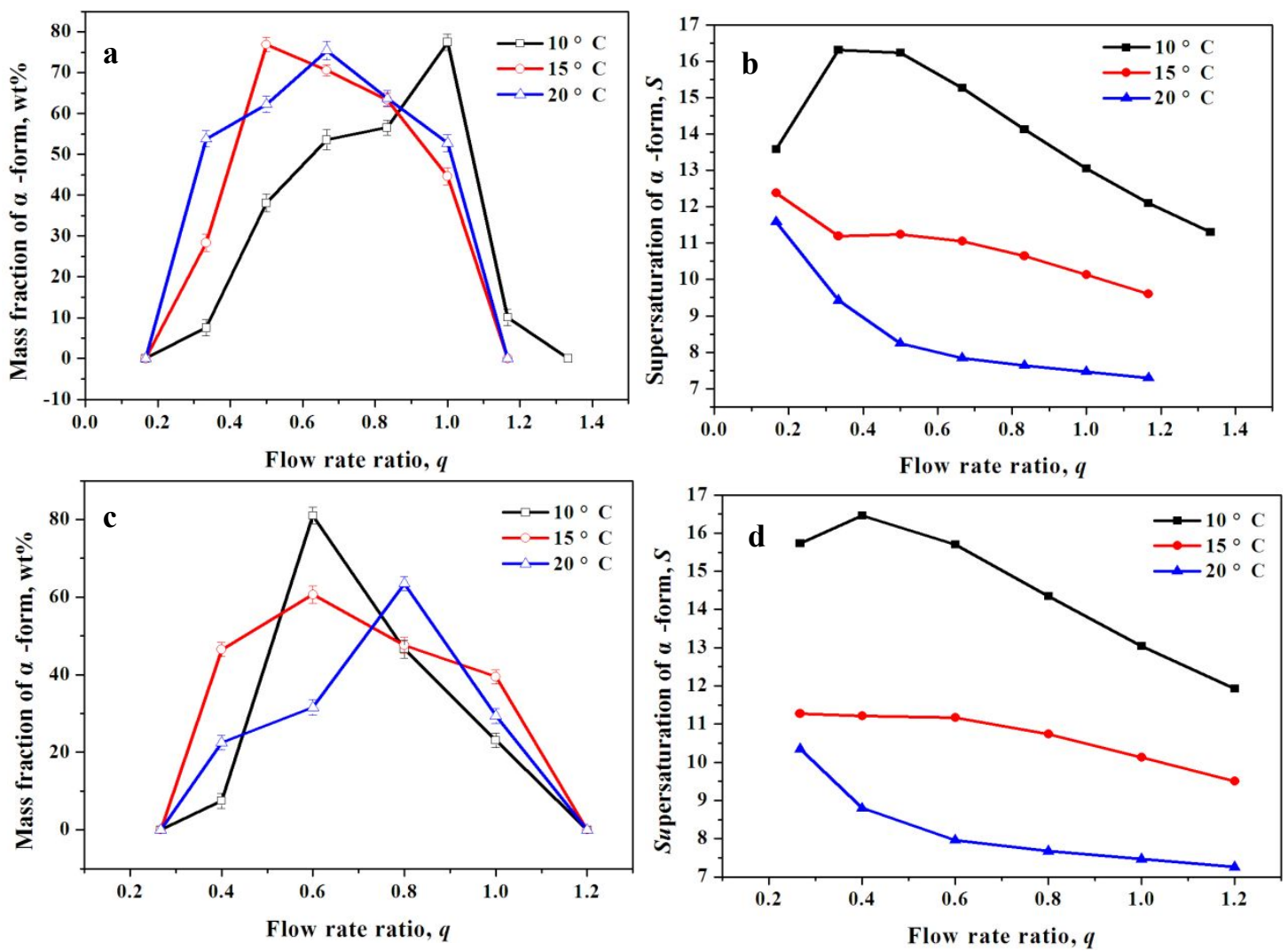

Figure S7. Polymorph selectivity of L-glutamic acid presented as the function of $q$, (a) the flow rate of antisolvent was $120 \mu \mathrm{L} / \mathrm{min}$, (c) the flow rate of antisolvent was $150 \mu \mathrm{L} / \mathrm{min}$. Relationship between final supersaturation and flow rate ratios (b) the flow rate of antisolvent was $120 \mu \mathrm{L} / \mathrm{min}$, (d) the flow rate of antisolvent was $150 \mu \mathrm{L} / \mathrm{min}$. The initial concentration of L-glutamic acid was $2.0000 \mathrm{~g}$ (L-glutamic acid)/100 g (water).

\section{References}

1. Acree Jr, W. E. Mathematical representation of thermodynamic properties: Part 2. Derivation of the combined nearly ideal binary solvent (NIBS)/Redlich-Kister mathematical representation from a two-body and three-body interactional mixing model. Thermochim. Acta 1992, 198, 71-79. 